\title{
Optical Properties of DLC:SiO and Ag Multilayer Films: Surface Plasmon Resonance Effect
}

\author{
Arvydas ČIEGIS *, Vitoldas KOPUSTINSKAS, Šarūnas MEŠKINIS, \\ Andrius VASILIAUSKAS
}

\author{
Institute of Materials Science of Kaunas University of Technology, Baršausko 59, LT-51423 Kaunas, Lithuania

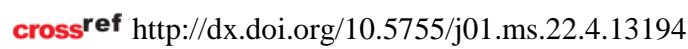

Received 21 September 2015; accepted 01 October 2015

\begin{abstract}
Diamond like carbon films containing silicon (DLC:SiOx) and „,conventional“ hydrogenated diamond like carbon (DLC) films were deposited by direct ion beam using anode layer ion source. Ag films were grown by unbalanced direct current magnetron sputtering. Structure of DLC:SiO films was investigated by Raman scattering spectroscopy. In the case of DLC: $\mathrm{SiO}_{\mathrm{x}}$ film deposited on Ag layer surface enhanced Raman scattering effect was observed. Optical properties of the different diamond like carbon and silver multilayers were studied. Annealing effects were investigated. Influence of the thickness of the diamond like carbon and Ag layers was investigated. Position of the plasmonic absorbance peak maximum of DLC:SiO and multilayers in all cases was redshifted in comparison with "conventional" diamond like nanocomposite films containing silver nanoclusters. It was explained by increase of the Ag nanoparticle size and/or increased probability of the oxidation of the embedded Ag due to the higher amount of oxygen in DLC:SiOx film in comparison with "conventional" diamond like carbon film.

Keywords: diamond like carbon, diamond like carbon nanocomposite containing silicon oxide, silver, multilayer film, Raman spectroscopy, surface plasmon resonance effect.
\end{abstract}

\section{INTRODUCTION}

Surface plasmon resonance effect received considerable attention of the researchers due to the very broad range of the possible applications including different elements of the optical nanocircuits [1-4], selective photo sensors of the increased sensitivity [5], biomedicine [6] and photovoltaics [4].

Nanoparticles of the noble metals (silver and gold) are the most often used plasmonic materials. In this case silver nanoparticles as a plasmonic material have their own advantages over gold nanoparticles. Particularly higher intensity of the surface plasmon resonance can be mentioned [7]. It should be mentioned that oxidation resistance of the silver nanoparticles can be increased by using ultra-thin protective coating [8-10]. Alternative approach is to use plasmonic multilayer films, which can be grown by widely used physical vapor deposition methods compatible with semiconductor device fabrication technology such as magnetron sputtering [4]. Such plasmonic multilayers can be easier integrated into the different microelectronic and optoelectronic devices in comparison with nanoparticles synthesized by wet chemical methods. Usually insulator/metal/insulator and metal/insulator/metal multilayers are used [4]. In this case surface plasmon resonance is excited at the metal layer and insulator layer interface [4].

One of the prospective insulator materials in this case is diamond like carbon (DLC). It is amorphous allotrope of carbon consisting of the $\mathrm{sp}^{3}$ bonded and $\mathrm{sp}^{2}$ bonded carbon atoms $[11,12]$. Hydrogenated diamond like carbon films in addition contain up to several tens atomic percent of

\footnotetext{
${ }^{*}$ Corresponding author. Tel.: +370-37-313432; fax: +370-37-314423

E-mail address: arvydas.ciegis@ktu.lt (A. Ciegis)
}

hydrogen [11, 12]. DLC films are hard, wear and corrosion resistant, chemically inert and biocompatible $[11,12]$. Optical and electrical properties of DLC films can be changed in a broad range [11,12]. Position of the nanoparticle surface plasmon resonance peak can be controlled by setting appropriate nanoparticle shape, size and inter particle distance [4]. In the case of the plasmonic multilayer position of the plasmonic peak depends on the refractive index of the insulator layer [4]. It should be mentioned that refractive index of DLC films (at $632 \mathrm{~nm}$ wavelength) can be changed in 1.6-2.5 range while maintaining high optical transparency [11-14]. Optical transparency of the diamond like carbon films can be increased while reducing internal stress by growing diamond like carbon films containing silicon oxide (DLC: $\mathrm{SiO}_{\mathrm{x}}$ ) [13]. There are a lot of the studies on plasmonic properties of the diamond like carbon films containing silver nanoparticles (see e.g., [15-19]). However diamond like carbon and silver multilayer films are less investigated [20]. Particularly there are no studies on DLC: $\mathrm{SiO}_{\mathrm{x}}$ and $\mathrm{Ag}$ multilayers or nanocomposite films. Therefore in the present research structure and optical properties of the diamond like carbon (or DLC:SiO $\mathrm{Ag}$ multilayers were investigated.

\section{EXPERIMENTAL TECHNIQUES}

In the present study hydrogenated diamond like carbon films were deposited by direct current ion beam deposition using anode layer ion source. DLC: $\mathrm{SiO}_{x}$ films were synthesized by using hexamethyldisiloxane $\left(\left(\mathrm{CH}_{3}\right)_{3} \mathrm{SiOSi}\left(\mathrm{CH}_{3}\right)_{3}\right.$ vapor and hydrogen gas mixture. „Conventional“ DLC films were grown for comparison purposes by using acetylene gas. Ag films were deposited by unbalanced magnetron sputtering of the silver target. 
Samples for the investigation of the optical properties were deposited on fused silica substrates, while samples for measurement of the Raman scattering spectra were grown on monocrystalline silicon substrates. For more information on fabricated and studied samples please see Table 1.

Table 1. Thickness of DLC and Ag multilayers investigated in the present study

\begin{tabular}{|c|c|c|c|}
\hline No & Multilayer & $d_{D L C}, \mathrm{~nm}$ & $d_{A g}, \mathrm{~nm}$ \\
\hline 1 & DLC:SiO$_{\times} / \mathrm{Ag} / \mathrm{DLC}: \mathrm{SiO}_{\mathrm{x}}$ & 53 & 10 \\
\hline 2 & DLC:SiO$_{\times} / \mathrm{Ag} / \mathrm{DLC}: \mathrm{SiO}_{\mathrm{x}}$ & 52 & 5 \\
\hline 3 & DLC:SiO$_{\times} / \mathrm{Ag} / \mathrm{DLC}: \mathrm{SiO}_{\mathrm{x}}$ & 52 & 5 \\
\hline 4 & $\mathrm{Ag} / \mathrm{DLC}: \mathrm{SiO}_{\mathrm{x}}$ & 52 & 5 \\
\hline 5 & $\mathrm{Ag} / \mathrm{DLC}: \mathrm{SiO}_{\mathrm{x}}$ & 27 & 5 \\
\hline 6 & $\mathrm{Ag} / \mathrm{DLC}$ & 28 & 5 \\
\hline 7 & $\mathrm{DLC} / \mathrm{Ag} / \mathrm{DLC}$ & 26 & 5 \\
\hline
\end{tabular}

Thickness of $\mathrm{Ag}\left(d_{A g}\right)$ layers was controlled by using quartz resonator. Thickness of DLC $\left(d_{D L C}\right)$ films was controlled by using deposition rate known from the previous studies [14] and setting appropriate deposition time. More information on deposition conditions, chemical composition and optical properties of DLC:SiOx films can be found in [14].

Raman scattering measurements were performed using a Raman microscope inVia (Renishaw) with $532 \mathrm{~nm}$ excitation. Integration time was $100 \mathrm{~s}$, power was $0.3 \mathrm{~mW}$, and grating groove density was 2400 grooves $/ \mathrm{mm}$.

Optical properties of the films were investigated using an optical spectrometer Avantes that is composed of a deuterium halogen light source (AvaLight DHc) and spectrometer (Avaspec-2048). The absorbance and reflectance of the films was analyzed in the wavelength region from $180 \mathrm{~nm}$ to $1100 \mathrm{~nm}$.

\section{EXPERIMENTAL RESULTS}

Structure of DLC: $\mathrm{SiO}_{\mathrm{x}}$ films deposited on Ag layer as well as DLC: $\mathrm{SiO}_{\mathrm{x}}$ films deposited directly onto the monocrystalline silicon substrate was studied by Raman scattering spectroscopy (Fig. 1). It can be seen that shape of the spectra in both cases is the same. Raman scattering spectra are typical for diamond like carbon $[11,12]$ with peculiarities common for $\mathrm{DLC}_{\mathrm{SiO}}$ films [13]. Particularly in all cases maximum of the main Raman scattering spectra peak is at the $1470 \mathrm{~cm}^{-1}$. Such a shifting from the position typical for $G$ peak of the conventional DLC film $\left(\sim 1530 \mathrm{~cm}^{-1}\right)$ can be explained by presence of the transpolyacetylene chains [13]. In the case of the Raman scattering spectra of $\mathrm{DLC}_{\mathrm{SiO}}$ film deposited on Ag layer surface enhanced Raman scattering (SERS) effect can be seen: intensity of the Raman spectra of DLC: $\mathrm{SiO}_{\mathrm{x}}$ film deposited on Ag layer is significantly higher than the intensity of the Raman spectra of DLC: $\mathrm{SiO}_{\mathrm{x}}$ film deposited directly on Si substrate. Optical absorbance and reflectance spectra of the plasmonic multilayers were studied. It can be seen in Fig. 2 that in the case of multilayer DLC: $\mathrm{SiO}_{\mathrm{x}} / \mathrm{Ag} / \mathrm{DLC}: \mathrm{SiO}_{\mathrm{x}}$ containing $10 \mathrm{~nm}$ thickness $\mathrm{Ag}$ interlayer, strong absorbance peak in $800-1100 \mathrm{~nm}$ range can be seen. However it can be seen in Fig. 2 a that reflectance of the multilayer in the same region is $\sim 100 \%$. Thus it seems that this multilayer acts as perfect mirror in
$800-1100 \mathrm{~nm}$ range. It is impossible correctly evaluate film absorbance due to such high reflectance.

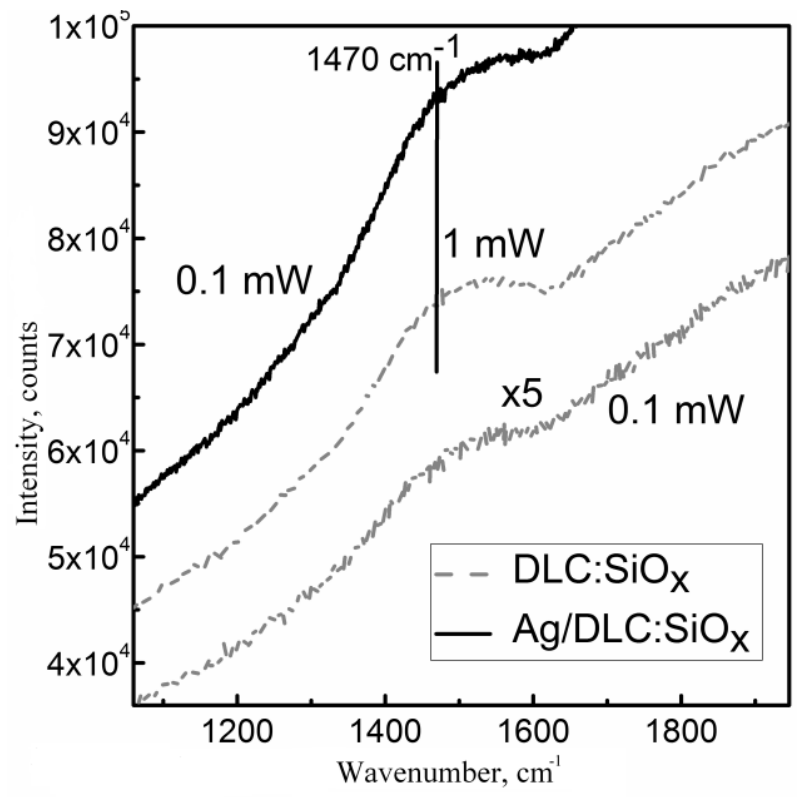

Fig. 1. Raman scattering spectra of DLC:SiO $x$ film and DLC:SiO$\times 1 / A g$ multilayer
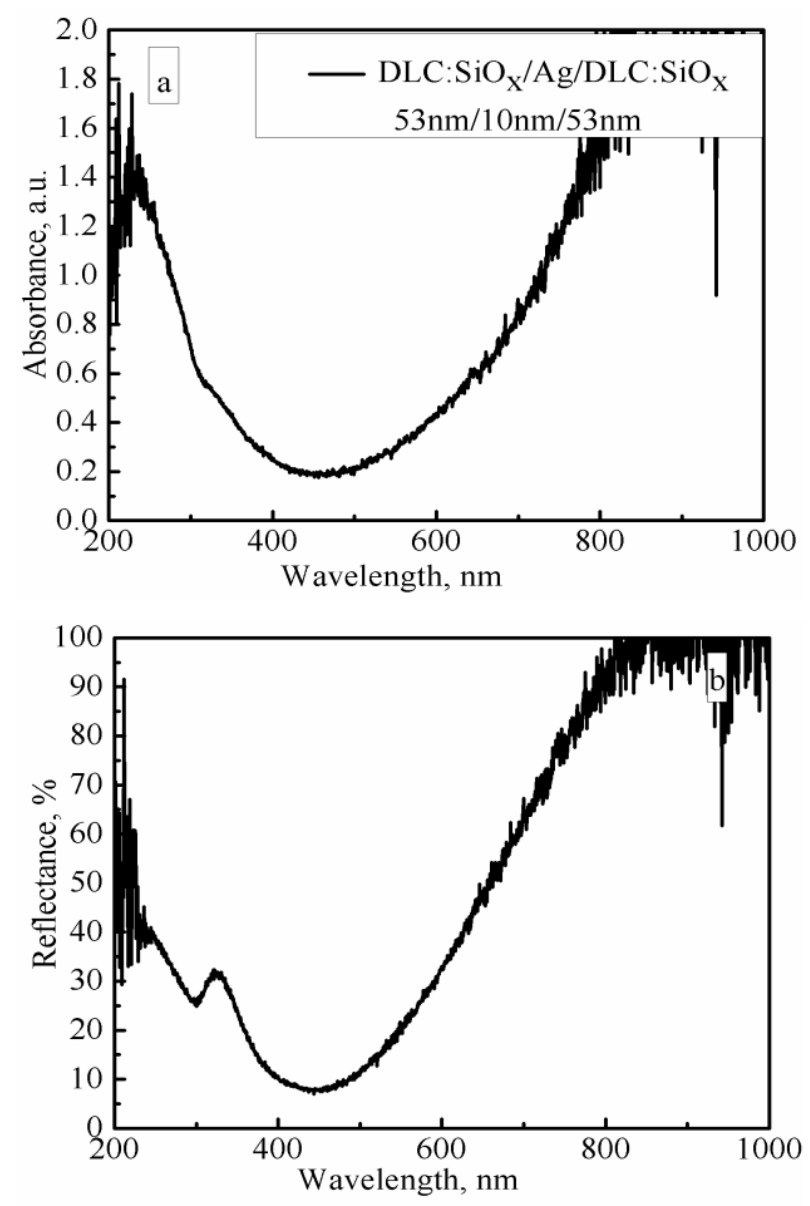

Fig. 2. Absorbance (a) and reflectance (b) spectra of multilayer DLC: $\mathrm{SiO}_{\mathrm{x}}-\mathrm{Ag}-\mathrm{DLC}: \mathrm{SiO}_{\mathrm{x}}$. Thickness of DLC: $\mathrm{SiO}_{\mathrm{x}}$ layer is $53 \mathrm{~nm}$, thickness of $\mathrm{Ag}$ film is $10 \mathrm{~nm}$

In the following experiments thickness of $\mathrm{Ag}$ layer was decreased from $10 \mathrm{~nm}$ to $5 \mathrm{~nm}$. It can be seen in Fig. 3 that in this case plasmonic absorbance peak redshifted. 
However, reflectance of the multilayers significantly decreased and did not exceed $30-35 \%$. Thus in this case absorbance spectra measurement data was reliable. It can be supposed that in this case $10 \mathrm{~nm} \mathrm{Ag} \mathrm{layer} \mathrm{was}$ continuous while $5 \mathrm{~nm} \mathrm{Ag}$ layer was non-continuous and consisted of the nanoclusters. Such an assumption is in good accordance with [21]. According to [21] transmittance and extinction spectra of $5 \mathrm{~nm}$ thickness $\mathrm{Ag}$ film were similar to the respective spectra of silver nanoparticles with surface plasmon resonance peak, while transmittance and extinction spectra of $10 \mathrm{~nm}$ thickness $\mathrm{Ag}$ film were typical to the continuous silver films. In addition, in [22] there were shown that $5 \mathrm{~nm}$ thickness $\mathrm{Ag}$ films consist of the isolated nanometric islands. It can be seen in Fig. 3 that plasmonic peak redshifted in the case of $\mathrm{Ag} / \mathrm{DLC}: \mathrm{SiO}_{\mathrm{x}}$ bilayers in comparison with the DLC: $\mathrm{SiO}_{\mathrm{x}} / \mathrm{Ag} / \mathrm{DLC}: \mathrm{SiO}_{\mathrm{x}}$ multilayer. In the case of the bilayer films both absorbance and reflectance was lower in $180-500 \mathrm{~nm}$ range. It should be mentioned that decrease of the DLC: $\mathrm{SiO}_{x}$ layer thickness in $\mathrm{Ag} / \mathrm{DLC}: \mathrm{SiO}_{\mathrm{x}}$ bilayer from 52 to $27 \mathrm{~nm}$ had no significant influence on absorbance and reflectance spectra of the bilayer films.
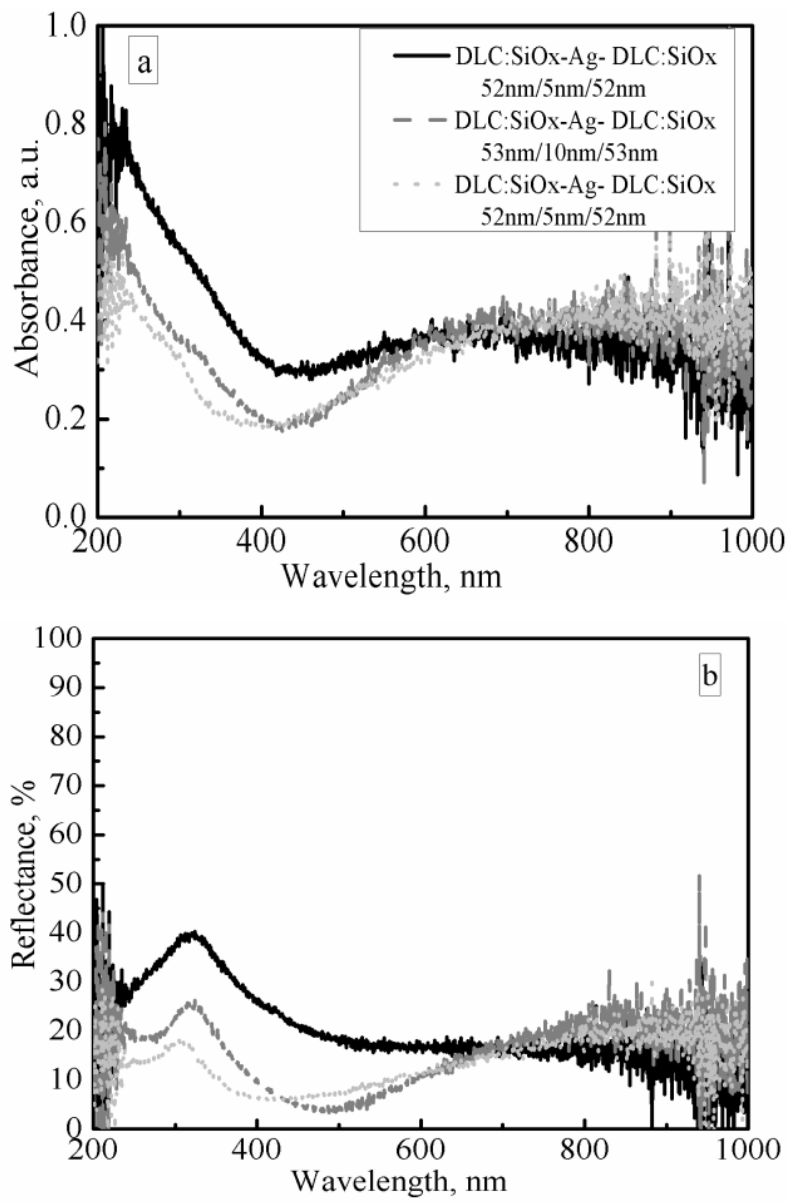

Fig. 3. Absorbance (a) and reflectance (b) spectra of multilayer DLC: $\mathrm{SiO}_{\mathrm{x}}-\mathrm{Ag}-\mathrm{DLC}: \mathrm{SiO}_{\mathrm{x}}$ (thickness of DLC: $\mathrm{SiO}_{\mathrm{x}}$ layer is $53 \mathrm{~nm}$, thickness of $\mathrm{Ag}$ film is $5 \mathrm{~nm}$ ) as well as $\mathrm{Ag}$ DLC: $\mathrm{SiO}_{\mathrm{x}}$ bilayers

Multilayers deposited by using $\mathrm{DLC}_{\mathrm{SiO}}$ and "conventional" hydrogenated DLC films are compared in Fig. 4, Fig. 5. It can be seen that in the case of DLC/Ag/DLC multilayer film no clearly pronounced plasmonic absorbance peak can be seen. Probably it can be explained by higher absorbance of DLC film in comparison with DLC: $\mathrm{SiO}_{x}$ [14]. Alternative explanation would be differences of the Ag film growth modes on DLC and DLC: $\mathrm{SiO}_{\mathrm{x}}$ surfaces. It can be mentioned that according to [23] minimal thickness of the continuous $\mathrm{Ag}$ film deposited on Ge layer is substantially than minimal thickness of the continuous Ag layer deposited on silicon dioxide. Surprisingly for DLC/Ag/DLC multilayer film some kind of the reflectance peak with maximum at $\sim 850 \mathrm{~nm}$ can be seen.
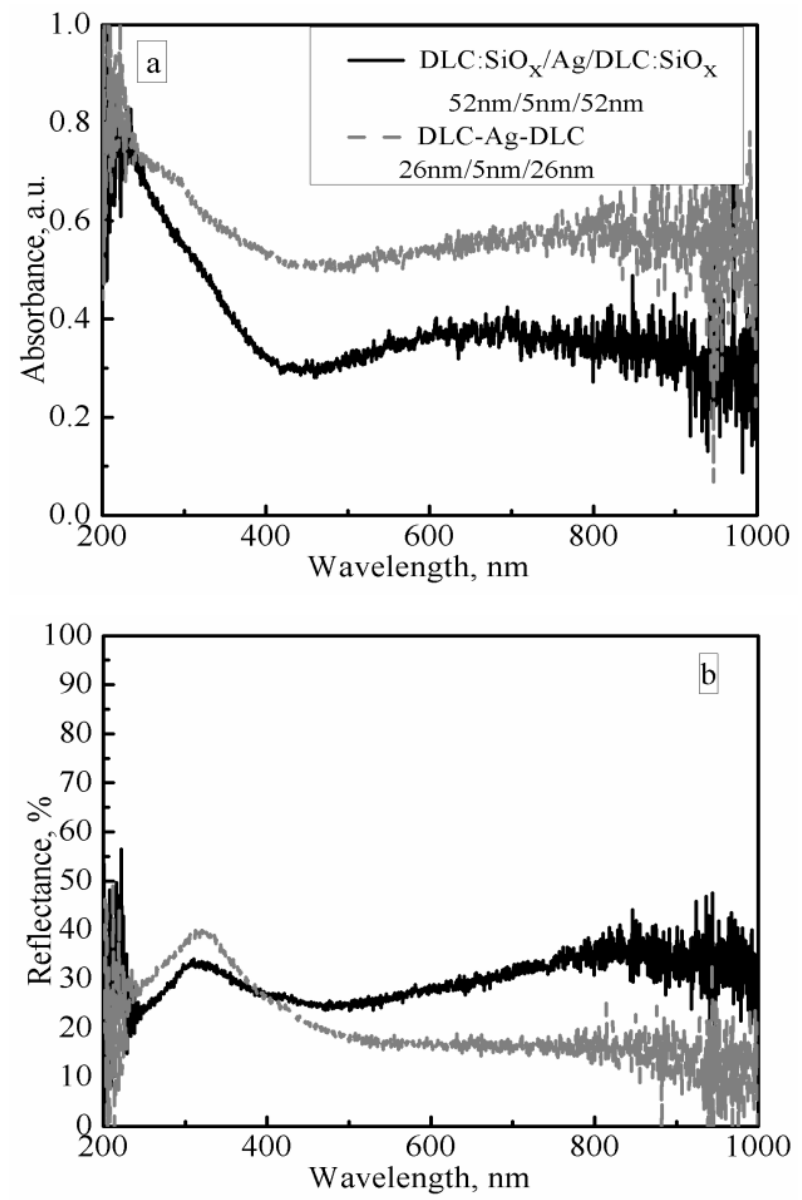

Fig. 4. Absorbance (a) and reflectance (b) spectra of multilayer DLC:SiO $/ \mathrm{Ag} / \mathrm{DLC}_{\mathrm{SiO}} \mathrm{Si}_{\mathrm{x}}$ and DLC/Ag/DLC films

In the case of the bilayer Ag/DLC:SiO ${ }_{x}$ and $\mathrm{Ag} / \mathrm{DLC}$ films plasmonic peak of the absorbance spectra of bilayer $\mathrm{Ag} / \mathrm{DLC}$ film is redshifted and less pronounced in comparison with the case of $\mathrm{Ag} / \mathrm{DLC}: \mathrm{SiO}_{\mathrm{x}}$ bilayer.

Annealing in air at $200{ }^{\circ} \mathrm{C}$ temperature of Ag/DLC bilayer resulted in appearance of the pronounced plasmonic peak with maximum in $550-600 \mathrm{~nm}$ range. It can be mentioned that vacuum evaporation of thin continuous Ag films followed by annealing results in the formation of nanoparticles in the form of islands [24, 25]. In addition, laser annealing of the $\mathrm{ZnO} / \mathrm{Ag} / \mathrm{ZnO}$ multilayer results in the formation of the $\mathrm{Ag}$ nanoparticles layer embedded between $\mathrm{ZnO}$ films [26]. Thus in our case it can be supposed that formation of the $\mathrm{Ag}$ nanoclusters took place as a result of the annealing, too. It should be mentioned that in this study in all cases position of the plasmonic peak maximum was at wavelengths $>600 \mathrm{~nm}$. 

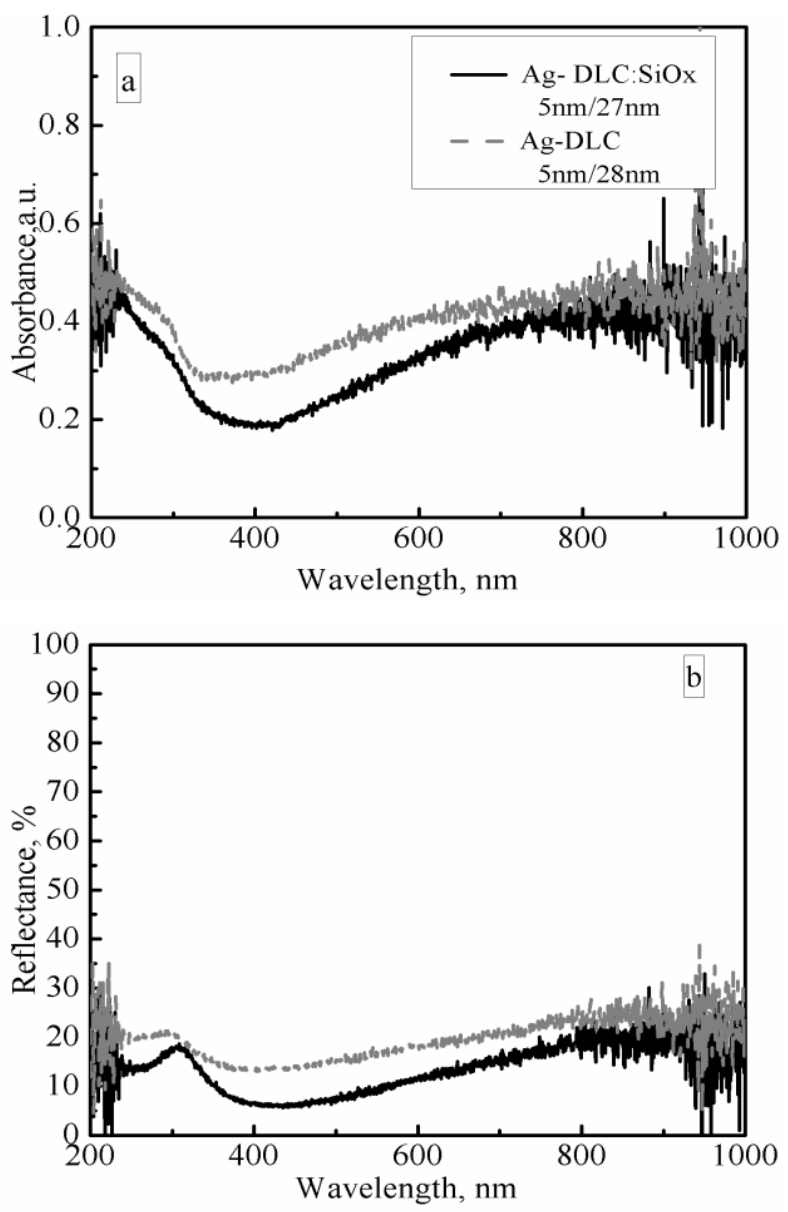

Fig. 5. Absorbance (a) and reflectance (b) spectra of bilayer $\mathrm{Ag} / \mathrm{DLC}: \mathrm{SiO}_{\mathrm{x}}$ and $\mathrm{Ag} / \mathrm{DLC}$ films

On the other hand, in the case of the DLC:Ag nanocomposites deposited by reactive magnetron sputtering position of the plasmonic peak was blueshifted. It was located at wavelengths $<500 \mathrm{~nm}[18,19]$. In addition in present study in all cases position of the plasmonic absorbance peak was located at the range of the higher wavenumbers in the case of the plasmonic multilayers fabricated by using DLC: $\mathrm{SiO}_{\mathrm{x}}$ is in comparison with multilayers containing DLC. Thus in the present study plasmonic peak position is redshifted despite refractive index of DLC: $\mathrm{SiO}_{\mathrm{x}}$ is lower than the refractive index of DLC [14]. There are two possible explanations of such behavior. Position of the surface plasmon resonance peak can redshift with increase of the Ag nanoparticle size [4]. Thus it can be supposed that size of the silver nanoclusters in the present study is higher than in $[18,19]$. On the other hand, oxidation of the silver nanoparticles results in redshift of the plasmonic peak, too $[19,27]$. In such a case use of DLC: $\mathrm{SiO}_{x}$ instead of the "conventional" DLC results in the increased probability of the oxidation of the embedded Ag due to the higher amount of the oxygen in the film. While in the case of the Fig. 6 oxidation of the silver nanoparticles can occur due to the annealing similarly to the [27].

\section{CONCLUSIONS}

Raman scattering spectra of DLC: $\mathrm{SiO}_{x}$ films deposited on $\mathrm{Ag}$ layer was typical for $\mathrm{DLC}: \mathrm{SiO}_{\mathrm{x}}$ films deposited directly onto the monocrystalline silicon substrate. In the case of the films deposited on both silver film and monocrystalline Si substrate maximum of the main Raman scattering spectra peak was at the $1470 \mathrm{~cm}^{-1}$. Such a shifting from the position typical for $G$ peak of the conventional DLC film $\left(\sim 1530 \mathrm{~cm}^{-1}\right)$ was be explained by presence of the transpolyacetylene chains.
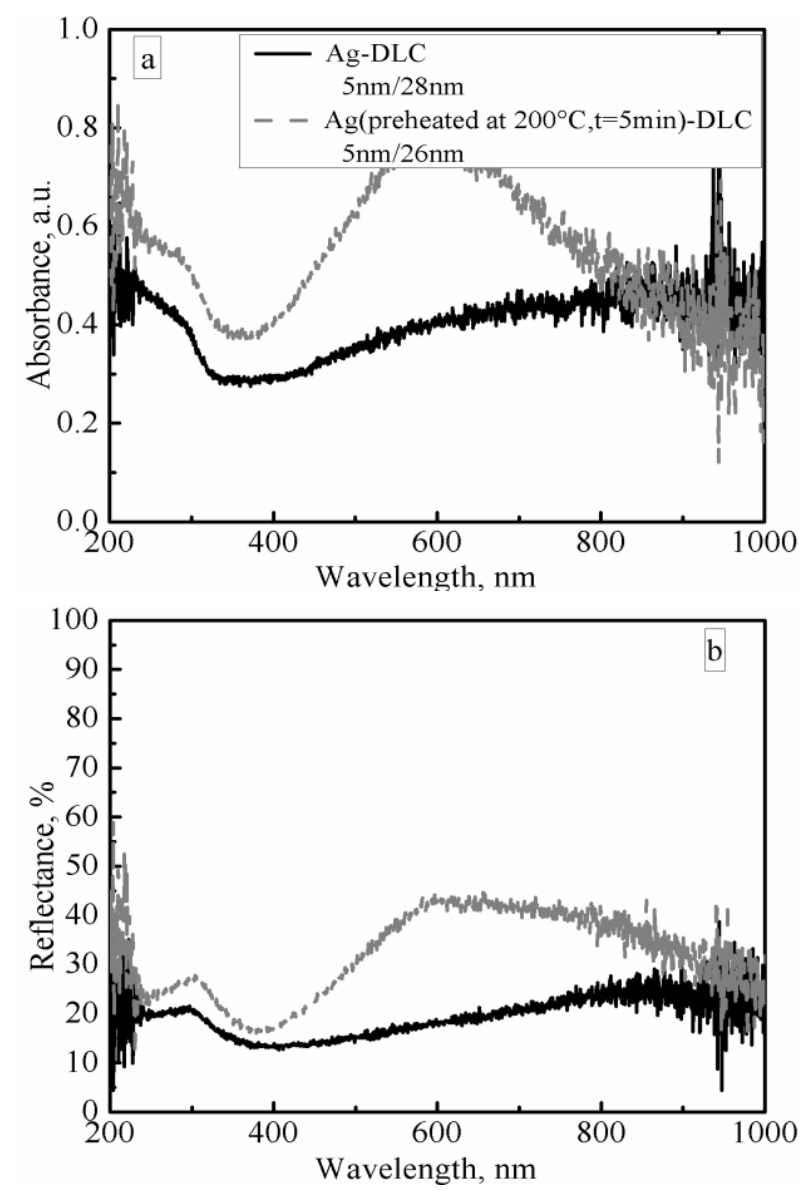

Fig. 6. Annealing effects on absorbance (a) and reflectance (b) spectra of bilayer Ag/DLC films

In the case of the Raman scattering spectra of DLC:SiO ${ }_{x}$ film deposited on Ag layer surface enhanced Raman scattering (SERS) effect was observed.

Study of the optical absorbance and reflectance spectra of the plasmonic multilayers DLC: $\mathrm{SiO}_{\mathrm{x}} / \mathrm{Ag} / \mathrm{DLC}: \mathrm{SiO}_{\mathrm{x}}$ containing $10 \mathrm{~nm}$ thickness $\mathrm{Ag}$ interlayer revealed strong $(\sim 100 \%)$ reflectance. Decreased of Ag film thickness to $5 \mathrm{~nm}$ resulted in substantially decreased reflectance. It can be supposed that $10 \mathrm{~nm} \mathrm{Ag} \mathrm{layer} \mathrm{was} \mathrm{continuous} \mathrm{while}$ $5 \mathrm{~nm} \mathrm{Ag} \mathrm{layer} \mathrm{consisted} \mathrm{from} \mathrm{the} \mathrm{nanoclusters.} \mathrm{Air}$ annealing at $200{ }^{\circ} \mathrm{C}$ temperature of $\mathrm{Ag} / \mathrm{DLC}$ bilayer resulted in appearance of the pronounced plasmonic peak with maximum in $550-600 \mathrm{~nm}$ range. It can be explained by formation of the $\mathrm{Ag}$ nanoclusters as a result of the annealing.

In this study in all cases position of the plasmonic peak maximum was at wavelengths $>600 \mathrm{~nm}$ while in the case of the DLC:Ag nanocomposites deposited by reactive magnetron sputtering position of the plasmonic peak was located at wavelengths $<500 \mathrm{~nm}$. Plasmonic peak position was redshifted despite refractive index of DLC: $\mathrm{SiO}_{\mathrm{x}}$ is lower than refractive index of DLC. It can be explained by 
increase of the Ag nanoparticle size and/or increased probability of the oxidation of the embedded $\mathrm{Ag}$ due to the higher amount of the oxygen in DLC:SiO ${ }_{x}$ film in comparison with "conventional" diamond like carbon $\mathrm{C}$ film.

\section{Acknowledgement}

This research was funded by the European Social Fund under the Global Grant measure (project No. VP1-3.1ŠMM-07-K-03-057).

\section{REFERENCES}

1. Yongqi, F., Xiuli, Z. Plasmonic Lenses: A review Plasmonics 5 2010: pp. $287-310$ http://dx.doi.org/10.1007/s11468-010-9144-9

2. Na L., Hentschel M., Weiss, Th., Alivisatos A.P., Giessen H. Three-dimensional Plasmon Rulers Science 332 2011: pp. $1407-1410$. http://dx.doi.org/10.1126/science.1199958

3. Dragoman, M., Dragoman, D. Plasmonics: Applications to Nanoscale Terahertz and Optical Devices Progress in Quantum Electronics 32 2008: pp. 1-41. http://dx.doi.org/10.1016/j.pquantelec.2007.11.001

4. Hayashi, Sh., Okamoto, T. Plasmonics: Visit the Past to Know the Future Journal of Physics D: Applied Physics 45 2012: pp. 1-24. http://dx.doi.org/10.1088/0022-3727/45/43/433001

5. Konstantatos, G., Sargent, E.H. Nanostructured Materials for Photon Detection Nature Nanotechnoly 5 2010: pp. 391-400.

6. Ahmad, M.Z., Akhter, S., Rahman, Z., Akhter, Sh., Anwar, M., Mallik, N., Ahmad, F.J. Nanometric Gold in Cancer Nanotechnology: Current Status and Future Prospect Journal of Pharmacy and Pharmacology 65 2013: pp. 634-651.

http://dx.doi.org/10.1111/jphp.12017

7. Peña-Rodríguez, O., Pal, U. Enhanced Plasmonic Behavior of Bimetallic (Ag-Au) Multilayered Spheres Nanoscale Research Letters 6 2011: pp. 1-5.

8. Formo, E.V., Mahurin, S.M., Dai S. Robust SERS Substrates Generated by Coupling a Bottom-Up Approach and Atomic Layer Deposition ACS Applied Material Interfaces 2 2010: pp. $1987-1991$.

http://dx.doi.org/10.1021/am100272h

9. Zhang, X., Zhao, J., Whitney, A.V., Elam, J.W., Van Duyne, R.P. Ultrastable Substrates for Surface-Enhanced Raman Spectroscopy: Al2O3 Overlayers Fabricated by Atomic Layer Deposition Yield Improved Anthrax Biomarker Detection Journal of American Chemical Society 128 2006: pp. $10304-10309$. http://dx.doi.org/10.1021/ja0638760

10. Jian Feng, L., Yi Fan, H., Yong, D., Zhi Lin, Y., Song Bo, L., Xiao Shun, Z., Feng Ru, F., Wei, Z., Zhi You, Z., De Yin, W., Bin, R., Zhong Lin, W., Zhong Qun, T. Shell-isolated Nanoparticle-Enhanced Raman Spectroscopy Nature 464 2010: pp. $392-395$ http://dx.doi.org/10.1038/nature08907

11. Robertson, J. Diamond Like Amorphous Carbon Material Science Engineering R 37 2002: pp. 129-281.

12. Robertson, J. Comparison of Diamond-Like Carbon to Diamond For Applications Physica Status Solidi A 205 2008: pp. $2233-2244$. http://dx.doi.org/10.1002/pssa.200879720

13. Meškinis, Š., Tamulevičienė, A. Structure, Properties and Applications of Diamond Like Nanocomposite $\left(\mathrm{Sio}_{\mathrm{x}}\right.$ Containing
DLC) films: a review Materials Science (Medžiagotyra) 17 (4) 2011: pp. $358-370$.

14. Kopustinskas, V., $\quad$ Meškinis, S̆., $\quad$ Tamulevičius, S., Andrulevičius, M., Čižiūtè, B., Niaura, G. Synthesis of the Silicon and Silicon Oxide Doped A-C:H Films from Hexamethyldisiloxane Vapor by DC Ion Beam Surface and Coatings Technology 200 2006: pp. $6240-6244$

http://dx.doi.org/10.1016/j.surfcoat.2005.11.101

15. Maya, F., Muhl, S., Peña, O., Miki-Yoshida, M. Synthesis and Characterization of Silver-Carbon Nanoparticles Produced by HighCurrent Pulsed arc Thin Solid Films 518 2009: pp. 1484-1488. http://dx.doi.org/10.1016/j.tsf.2009.09.090

16. Hussain, S., Roy, R.K., Pal, A.K. Incorporation of Silver Nanoparticles in DLC Matrix and Surface Plasmon Resonance Effect Materials Chemistry and Physics 99 2006: pp. 375-381. http://dx.doi.org/10.1016/j.matchemphys.2005.11.008

17. Zoubos, H., Koutsokeras, L.E., Anagnostopoulos, D.F., Lidorikis, E., Kalogirou, S.A., Wildes, A.R., Kelires, P.C., Patsalas, P. Broadband Optical Absorption of Amorphous Carbon/Ag Nanocomposite Films and its Potential for Solar Harvesting Applications Solar Energy Materials and Solar Cells 117 2013: pp. 350-356 http://dx.doi.org/10.1016/j.solmat.2013.06.019

18. Faruque Ahmed, Sk., Myoung-Woon M., Kwang-Ryeol L. Effect of Silver Doping on Optical Property of Diamond Like Carbon Films Thin Solid Films 517 2009: pp. 4035-4038. http://dx.doi.org/10.1016/j.tsf.2009.01.135

19. Meškinis, Š., Čiegis, A., Vasiliauskas, A., Tamulevičienė, A., Šlapikas, K., $\quad$ Juškẻnas, R., $\quad$ Niaura, G., $\quad$ Tamulevičius, S. Plasmonic Properties if Silver Nanoparticles Embedded in Diamond Like Carbon Films: Influence of Structure and Composition Applied surface science 317 2014: pp. 1041-1046. http://dx.doi.org/10.1016/j.apsusc.2014.09.032

20. Chiba, K., Takahashi, T., Kageyama, T., Oda, H. Low-emissivity coating of amorphous diamond-like carbon/Ag-alloy multilayer on glass Applied Surface Science 246 2005: pp. 48-51. http://dx.doi.org/10.1016/j.apsusc.2004.10.046

21. Junbo, G., Rucheng, D., Zhongping, W., Zengming, Z. Thickness Dispersion of Surface Plasmon of $\mathrm{Ag}$ Nano-thin Films: Determination by Ellipsometry Iterated with Transmittance Method Scientific Reports 5 2015: pp. 1-5.

22. Haoyan, W., Eilers, H. From Silver Nanoparticles to Thin Films: Evolution of Microstructure And Electrical Conduction on Glass Substrates Journal of Physics and Chemistry of Solids 70 2009: pp. 459-465. http://dx.doi.org/10.1016/j.jpcs.2008.11.012

23. Weiqiang, C., Thoreson, M.D., Satoshi, I., Kildishev, A.V., Shalaev, V.M. Ultra-thin Ultra-Smooth and Low-Loss Silver Films on a Germanium Wetting Layer Optic express 18 2010: pp. 5124-5134

24. Kvítek, O., Siegel, J, Hnatowicz, V., ŠvorIík, V. Noble Metal Nanostructures Influence of Structure and Environment on their Optical Properties Journal of Nanomaterials 2013: pp. 1-15. http://dx.doi.org/10.1155/2013/743684

25. Sreenivasan, M.G., Shweta, M., Srikanth, T., Bodh, R.M. Dependence of Plasmonic Properties of Silver Island Films on Nanoparticle Size and Substrate Coverage Journal of Nanomaterials 2013: pp. 1-8.

26. Koleva, M. E., Nedyalkov, N.N., Atanasov, P.A. Effect of the Plasmon-Exciton Coupling on the Optical Response of a Zno/Ag/Zno Nanocomposite Journal of Physics: Conference Series 2014: pp. 1-4. http://dx.doi.org/10.1088/1742-6596/514/1/012031

27. Mohapatra, S., Mishra, Y.K., Ghatak, J., Kabiraj, D., Avasthi, D.K. Surface Plasmon Resonance of Ag Nanoparticles Embedded in Partially Oxidized Amorphous Si Matrix Journal of nanoscience and nanotechnology 8 2008: pp. 4285-4289. 